ISSN: 2576-2141

\title{
Qualitative Inquiry with Adolescents: Strategies for Fostering Rich Meaning Making in Group Interviews
}

\author{
Kate H. Guthrie ${ }^{1}$ \\ Piedmont College, Georgia, USA
}

\begin{abstract}
Qualitative inquiry with adolescents is challenging, especially in the field of educational research in which adults are often the gatekeepers of 'right' and 'wrong' answers. To help diminish power dynamics, group interviews are a common method for inquiry. However, the intense desire to fit in with a group of peers and the risks associated with confidentiality can influence how adolescents respond. In this article, I summarize common obstacles to group interviews with adolescents followed by strategies qualitative researchers can employ to foster richer meaning making among adolescent participants to help create a space suitable for discussion of personal or sensitive topics and capture the rich, shared meaning making that can happen as a result of the group's social interaction in the group interview. I conclude with implications for researchers and teachers of qualitative research methods
\end{abstract}

KEYWORDS: Educational Research, Group Cohesion, Interview Activities, Interviewing Adolescents, Teaching Qualitative Research.

Qualitative inquiry with adolescents can offer the field of education insight into adolescents' experiences as students and stakeholders in education. Educational research involving adolescent participants often relies heavily on adult interpretation, and because adolescents are situated with little power in researcher-researched relationships, engaging in qualitative inquiry can be challenging.

To combat some of the challenges of interviewing adolescents, group interviews ${ }^{2}$ are recommended as a favorable method of data collection among this population. Compared to one-on-one interviews, group interviews may feel more natural to adolescents as they regularly construct collective meanings with their peers in group environments (e.g., classroom, friendship circles) (Eder \& Fingerson, 2001), and they may feel more comfortable responding in a group environment when the researcher is outnumbered. Furthermore, group interview settings often elicit different participant responses than one-on-one environments (Barbour, 2007; Eder \& Fingerson, 2001; Ozfidan \& Burlbaw, 2016; Roulston, 2010; Wilkinson, 1998; 2008). Interaction of group participants can trigger memories, stimulate discussions, and encourage disclosure and detailed accounts of shared responses (Wilkinson, 1998, 2008). However, because adolescence is a period where youth experience an intense desire to fit in with their peers (Erickson, 1980), there are obstacles to facilitating group environments in which adolescents feel comfortable sharing their thoughts, feelings, and experiences aloud.

\footnotetext{
${ }^{1}$ Correspondent Author E-mail: kguthrie@piedmont.edu

${ }^{2}$ Although the field of qualitative inquiry notes the differences between focus groups and group interviews, I have chosen to use the term group interview to represent a scenario in which the number of participants interviewed outnumber that of the researchers. Thus, some of the literature cited here refers to literature about both focus groups (e.g. Barbour, 2007; Wilkinson, 2008) and group interviews (e.g. Roulston, 2010).
} 
Norris et al. (2013) listed the following as challenges of conducting group interviews with adolescents: (a) there is a declining social trust among adolescents that can affect the quality and quantity of information shared, (b) adolescents have an intense need for peer approval and may show discomfort with answering direct questions in front of peers, (c) adolescents may find it difficult to talk about sensitive topics, (d) adolescents often have a short attention span which can create restless energy, and (e) adolescents may only share socially desirable responses with the group. Although some of these challenges may be apparent to educators, parents, or other adults who work closely with adolescents, they may not be as obvious to researchers who have had little access or experience in working with adolescent participants or who have been removed from working in educational environments for some time.

The purpose of this article is two-fold: (1) to discuss obstacles to group interviews with adolescents and (2) offer suggestions for how to design and facilitate effective group interviews with adolescents inspired by concepts from the field of group work. Even though some of the strategies presented are practiced in therapeutic relationships, in general, interviewers should avoid establishing a therapeutic relationship with participants (Seidman, 2013). For qualitative researchers, I encourage the reader to consider how skills and strategies from the field of group work can strengthen one's ability to facilitate effective group interactions and discussions. My aim is for the reader to consider these strategies as stepping-stones for reflection and practice of qualitative inquiry among groups of adolescents in schools.

This article is organized into four parts. Part one introduces the reader to the theoretical underpinnings of meaning making in the group context. Part two describes how meaning making in group interviews is influenced by group cohesion and trust. Part three summarizes three primary threats to group cohesion and trust when interviewing groups of adolescents: power dynamics, peer influence, and confidentiality. And, part four presents several strategies to help researchers overcome these obstacles inspired by literature and my own experiences in working with groups of adolescents. I conclude with implications for researchers and instructors of qualitative research methods.

\section{An Interactionist Perspective of Meaning Making}

Based in the symbolic interactionism tradition (Mead, 1934), an interactionist perspective provides the framework for understanding how adolescent participants make meaning in social situations. In this tradition, meaning is not created by one's individual experiences but instead, is created out of the social interaction with others (Blumer, 1969; Mead, 1934). According to Mead (1934), we are social beings, and in the midst of social interaction, there is a giving and receiving of certain gestures. We then undergo a state of self-interaction in order to interpret those gestures into meanings. Through this process, we collect, analyze, discard, or fuel aspects of meaning and then interpret and respond accordingly. Thus, we are guided by the meanings we place on our experiences with others (Blumer, 1969).

In group settings, we have the capacity to view ourselves as others see us. We can define a situation and organize ourselves to confirm our socially defined role or expectation of behavior (Prasad, 2005). By seeing how we fit into certain situations, we are then able to decide how to act in those situations. From this perspective, everything adolescent participants may say during a group interview is influenced by their sense of how the other participants, and the adult researcher, will react to what they say (see Morgan, 2012).

By applying this interactionist perspective, qualitative researchers can shape the way meaning is constructed in group interviews. A study's design and methods, the ways in which a researcher attends and responds to participants' conversations, and if or how the researcher encourages participants to attend to and respond to each other all have potential influence on the shared meaning created by participants. Fostering a group environment where meaning 
making can take place is thus a priority in conducting group interviews with adolescents, and one of the primary requirements for facilitating rich meaning making is enabling the group's ability to establish group cohesion and trust.

\section{The Foundation for Rich Meaning Making: Group Cohesion and Trust}

What is rich meaning making? In qualitative inquiry, researchers use a variety of methods to gather insights into participants' thoughts and feelings regarding their lived experiences. When asking adolescent participants to make meaning of their experiences, we are asking them to reconstruct their experiences by bringing those experiences to their attention, reflect on them, and then assign meaning to them (Schutz, 1967). Richness is characterized by details, thick descriptive, and careful construction. Collecting rich data enhances the credibility of qualitative research (Tracy, 2010).

One method of capturing rich meaning making is through qualitative interviews, either one-on-one or with groups of participants. More than just a verbal exchange of information through a stimulus (i.e. an interviewer's question) and response (i.e. an interviewee's answer), qualitative interviews can be viewed as a discourse between the interviewer and interviewee in an attempt to reach a joint construction of meaning (Mishler, 1986). An interview is an activity in which both the interviewer and interviewee(s), "through repeated reformulations of questions and responses, strive to arrive together at meanings that both can understand" (Mishler, 1986, p. 65). Together, they engaged in shared meaning making. To be clear, in the group interview context, this shared meaning is not the same as all of the participants in a group agreeing with each other (Morgan, 2012). Through sharing and comparing their responses with each other, group interview participants create a shared understanding of the complexity of meaning through discourse and reflection. As deMarrais (2004) reminded us, the researcher participates in the construction of the group's shared meaning experience by entering into this discourse by attending and responding to the conversation. Since shared meaning making within group interviews can be risky for adolescents (Norris et al., 2013), we look to the field of group work to learn about how fostering a sense of group cohesion and trust can create a space in which adolescents feel comfortable sharing rich details of their lived experiences.

Group cohesion has a variety of definitions in the field of group work. Yalom (2005), in his work with group psychotherapy, defined group cohesiveness as a sense of "groupness" or "we-ness" that translates to attractiveness towards the group and its members. Johnson and Johnson (2013) also described group cohesiveness as attraction and a "desire to remain in the group" (p. 97). In the context of group interviews, if adolescent participants experience the group as being welcoming and a source of belonging, the group's cohesiveness can encourage the "affective sharing of one's inner world" (Yalom, 2005, p. 56). Cohesion here does not mean that the participants desire to be the same-which is neither the goal in group work nor the goal of qualitative inquiry. Instead, group cohesion is a characteristic of group dynamics that influences the setting of the interview and the adolescent participants' comfortability in reflecting, exploring, and sharing their experiences aloud.

In order for a group to be cohesive, there must be a sense of trust among the group members. Johnson and Johnson (2013) claimed the crucial elements to developing and maintaining trust in group work are openness, sharing, acceptance, support, and cooperative intentions. One must not forget-acceptance among adolescents is a big deal. They are most often motivated by peer acceptance, while at the same time, beginning the journey of selfacceptance. Acceptance in terms of group work or group interviews does not translate to agreement, but rather the group's ability to listen attentively without expressing judgement or criticism towards each other. The more trustworthy group members are, including the group leader, the more likely they are to disclose their thoughts, feelings, and experiences with the group. 
In qualitative research, the term trustworthiness describes a research study's quality (Freeman et al., 2007), or more specifically, a study's credibility, transferability, dependability, and confirmability (Lincoln \& Guba, 1985). However, in the current context, I am using trustworthiness to describe not only the qualitative researcher's ability to maintain confidentiality, but also the ability to respond to an adolescent participant's risk-taking (e.g. sharing their thoughts, feelings, and experiences within the group interview) in a way that ensures the participant benefits from your acceptance and support in the inquiry. Trustworthy interviewers are respectful, nonjudgmental, and non-threatening (Merriam \& Tisdell, 2016). They listen more and talk less, aware that too much or ill-timed exploration of participants' responses can make participants respond defensively (Seidman, 2013). If an interviewer exhibits these characteristics with a positive attitude and orientation, in addition to encouraging adolescent participants to adopt similar behaviors, then group cohesiveness is more likely. Groups that are highly cohesive have higher levels of engagement (MacKenzie et al., 1987) and greater levels of self-disclosure (Yalom, 2005). Thus, a researcher's ability to encourage and establish group cohesion and trust can influence the group's ability to co-construct meaning through sharing and comparing their thoughts, feelings, and experiences (Morgan, 2012).

\section{Threats to Group Cohesion and Trust in Group Interviews with Adolescents}

Unfortunately, rich meaning making, group cohesion, and trust are not always easily accessible to adolescent participants. Researchers who gather adolescents for group interviews, without considering the obstacles that may prevent adolescents from being able to co-construct meaning making, may well be disappointed in the poor quantity and quality of data collected. Therefore, this section includes a discussion of three primary obstacles to rich meaning making in group interviews: power dynamics, peer influence and group norms, and confidentiality. These threats to group cohesion and trust are complex and often overlap in the midst of adolescent development and social interaction.

\section{Unequal Power Dynamics}

Power dynamics, either between the researcher and participants or among the group of participants, can threaten the group's ability to be cohesive and build a sense of trust. In the context of qualitative inquiry, Seidman (2013) described power as "who controls the direction of the interview, who controls the results, [and] who benefits" (p. 101) and claimed the researcher-participant relationship has the potential to be power-laden and unequal. Group interviews are thus often recommended as a method to address power imbalances in the researcher-participant relationship. Compared to one-on-one interviews, group interviews can help minimize the power differential as the number of participants outweighs the number of researchers (Dixon, 2015; Eder \& Fingerson, 2001; Roulston, 2010). However, group interviews with adolescents does not instantly guarantee a more equitable power relationship simply because the interviewer is outnumbered.

Power can be experienced directly, primarily through the relationships and interactions of those in the group (Johnson \& Johnson, 2013). This includes the direct researcher-participant relationship and the participants' relationships to each other. According to Mayall (1999), children and adolescents are regarded as a "minority group in their social positioning within local and national power structures" (p. 10), and even within the family, children and adolescents have little power to participate in decision making. In traditional educational settings, adults tend to hold the most power and decision-making responsibilities. Throughout their years of schooling, adolescents' daily activities are guided by a strict bell schedule, and they have learned that the adults in the classrooms are the ultimate judges of right and wrong answers. Power can also be experienced directly through participants' relationships and 
interactions with their peers in the group. For example, the 'popular' students may hold more power in certain groups, and if the participants know each other, they carry with them their past experiences in classrooms or in the hallways.

On the other hand, adolescents in schools also experience power indirectly through group norms and values (Johnson \& Johnson, 2013). They spend most of time at school in groups (e.g. classes, clubs, teams, groups of friends, etc.) and there often exists a hierarchy of power in each of the different groups to which they belong. Some students hold more power, or privilege, compared to their peers due to academic, social, cultural, socioeconomic, or other socially prescribed status. Depending on the composition of the group, adolescents are often quick to note which of their peers holds power or privilege and which of their peers do not. For a group of adolescents who already know each other, these power roles have likely already been established outside of the group interview.

\section{Peer Influence}

Another threat to group cohesion and trust in group interviews with adolescents is the increased emphasis of obtaining peer approval that naturally develops in adolescence (Erikson, 1980). Berg et al. (2013) claimed adolescence as a stage of development "characterized by conflict, questioning of values, a bewildering array of choices, confusing physiological changes, and an overwhelming need for approval by peers" (p. 171), and these characteristics influence the ways in which adolescents interact and respond in group environments. Conforming to a group's "rules of the game" is usually a requirement for acceptance and continued membership in the group (Johnson \& Johnson, 2013), and yet, adolescents often oscillate-breaking the "rules" of one group in order to find belonging in another group.

As summarized by Forsyth (2006), there are three sources of group influence on members: informational influence, normative influence, and interpersonal influence. Informational influence describes the interpersonal processes that promote change by challenging the correctness of a group members' beliefs or the appropriateness of their behavior directly or indirectly. Normative influence describes the personal and interpersonal processes that cause individuals to feel, think, and act in ways that are consistent with social norms, standards, and conventions. Interpersonal influence describes the social influence that results from other group members selectively encouraging conformity and discouraging nonconformity (Forsyth, 2006). In Table 1, I present possible scenarios of how these three sources of group social influence may be experienced by an adolescent participant in the midst of a group interview. Although the messages portrayed by these sources of influence may be positive, messages that are negative or intimidating in nature have the potential to threaten group cohesion, thus hindering participants' comfort and willingness to share aloud in the group interview.

These sources of social influence may already be established as group norms among participants. Berg et al. (2013) defined group norms as "implicit or explicit agreed-upon standards that govern behavior in the group" (p. 182). In the case that your adolescent participants know each other and/or have been grouped together in the classroom or other educational environment, paying particular attention to the group's norms can help you better understand how shared meaning making and disclosure of information are expressed in the group. For example, you may have a participant who has always been looked to as being the spokesperson of the group. Or, you may have two participants who are especially quiet and have learned that speaking up in opposition of their classmates leads to being ostracized. Disrupting the group norms may or may not play to the advantage of facilitating richer meaning making in the group, and strategies related to establishing group norms for your group interview are discussed later in this article. 
Table 1

Scenarios of Group Social Influence from the Perspective of an Adolescent Participant

\section{Source of Group Possible Scenarios}

Social Influence

Informational When Mariah shared her experience, everyone seemed to nod their heads influence in agreement with her. The group must agree with her more than they agree with Sam.

Jeremy answered the interviewer's question with disagreement. I should take a second to consider if I disagree with the interviewer, too.

Normative Everyone raised their hand to agree with Veronica, and I accept that her influence response is a reflection of my own.

I am tired of always answering adults' questions. Most of the group is slouching in their seats with their arms crossed. If I participate fully, I risk not fitting in.

Interpersonal When Raphael spoke in favor of Response A, the group laughed in influence disbelief and called him a 'traitor.'

When Trey spoke in favor of Response B, the group agreed with him.

Note. Scenarios adapted from Forsyth (2006) to the context of group interviews with adolescents.

Ultimately, recognizing that adolescents gain most of their understanding of the world in the midst of social interaction at school, in the classroom, and amongst their peers should have bearing on how a researcher designs and implements group interviews as a way of collecting data. Ignorance of how adolescent participants may experience the group interview may result not only in poor data quality but also the increased chance that the participants may experience unnecessary risks or discomforts.

\section{Confidentiality}

The final threat to group cohesion and trust is that of confidentiality. Confidentiality is directly linked to establishing a sense of trust within the group. When working with human subjects in research contexts, and with minors in particular, maintaining confidentiality of participants' identities and disclosures is critical. Conducting group interviews in the context of schools may pose certain risks to students who may hesitate to share their thoughts, feelings, and experiences as they relate to authority figures or peers they see on a daily basis. Additionally, researchers are held to ethical standards of reporting situations or responses from minors that elicit statements related to abuse, mistreatment, neglect, drug use, or other criminal behaviors (The National Commission for the Protection of Human Subjects of Biomedical and Behavioral Research, 1979).

When conducting group interviews with adolescents, the concept of confidentiality is broadened to also include the notion of holding the conversations shared within the group privately. Confidentiality is challenged as participants voluntarily offer responses in front of other participants, and although the researcher encourages group members to hold the groups' conversations private, the researcher cannot guarantee that participants will keep what is shared within the group private (Roulston \& Liljestrom, 2010). When working with adolescents, it is 
possible that a participant may share what is said in the group interview with others (e.g., peers, adults, etc.) who were not present, thus breaking the confidentiality of the group. If adolescent participants believe their peers may break confidentiality of the group, they may be more reluctant to self-disclose and participate in shared meaning making. If you plan to discuss sensitive topics with your adolescent participants, reconsider as to whether the group interview method is the most appropriate and beneficial for your participants.

\section{Strategies for Fostering Rich Meaning Making in Group Interviews with Adolescents}

The following group interview suggestions have been influenced by the fields of group work and my own experiences of working with adolescents in a variety of contexts, primarily as a middle and high school math teacher. I spent the majority of my waking hours each weekday immersed in a sea of teenagers-as a classroom teacher, hallway and lunchroom monitor, after school club organizer, and athletic coach. In addition, I have conducted several studies and pilot research experiences which included group interviews with adolescents (e.g., Guthrie, 2020). From the literature and from my experiences, I have developed the following strategies, which can be used in designing and conducting group interviews with adolescents to help encourage and build group cohesion and trust.

Strategies include:

- Understanding stages of group development

- Paying attention to the influence of the school setting

- Defining your leadership style

- Using introductory activities

- Encouraging effective group norms

- Incorporating humor

- Encouraging written reflections in data collection

- Designing your study to benefit participants

You will find that these strategies can be implemented independently or in conjunction with others in order to enhance rich meaning making among adolescent participants.

\section{Understand Stages of Group Development}

Throughout the history of group work and group dynamics, there have been several models proposed that demonstrate the stages of group development. I have found Tuckman and Jensen's (1977) stages of small group development to be easy to follow and appropriate for application to qualitative inquiry with group interviews. They described five sequential stages of development: Forming, Storming, Norming, Performing, and Adjourning. In Table 2, I summarize these stages and provides suggestions for how they can be applied to a single group interview or series of group interviews. Understanding each stage of group development can be particularly helpful in the research context when forming groups of participants that do not already know each other (Finch et al., 2014).

Although these stages are presented linearly, they vary in duration and some stages can reoccur throughout the formation of the group, and each stage may vary in duration. In other words, if group interviews are conducted across multiple sessions, the group may experience some of the stages (e.g. Forming, Storming, Norming) repeatedly over time. Each session may begin with brief experiences of Norming before settling into the Performing stage. Recall that adolescence is a turbulent time of development and conducting group interviews across multiple 
sessions means that the participants will have had multiple opportunities to be socially influenced outside of the group.

Table 2

Applications of the Stages of Group Development to Group Interviews

\begin{tabular}{ll}
\hline Stage & Description \\
\hline Forming & $\begin{array}{l}\text { This stage often takes place at the } \\
\text { beginning of the group formation, } \\
\text { including the time the facilitator designs } \\
\text { and initiates the group. The facilitator } \\
\text { focuses on creating the group and helping } \\
\text { group members get settled and comfortable } \\
\text { with the purpose of their group. }\end{array}$ \\
Storming & $\begin{array}{l}\text { In this stage, the group focus shifts from } \\
\text { wanting acceptance, approval, and } \\
\text { commitment to one that has tension, } \\
\text { conflict, and even competition as some } \\
\text { group members may try to assert } \\
\text { dominance or power in the group. }\end{array}$ \\
Norming & \\
& \\
This stage describes the process of \\
developing a feeling of cohesion within the \\
group. Cohesive groups are more likely to \\
be honest, have better trust, have higher \\
emotional closeness, seek out intimacy, and \\
manage conflicts respectfully.
\end{tabular}

Application(s) to Group Interview(s)

This stage reflects the period of time the

researcher begins to design the group

interview study, contact and recruit

participants, and any other introductory

communications that take place before

or at the initial start of the group

interview(s).

This stage can be viewed as the beginning moments or periods of time in

which participants adjust to the environment of the group interview. This can include questions and conversations regarding the introduction and review of the purpose of the group interview(s), individual introductions of the participants, and beginning interview questions that are introductory in nature.

This stage is when groups begin to trust each other, through a statement of group expectations, through activities, or through the beginning stages of group discussion. The interviewer will need to pay careful attention that the 'norming' of the group does not mask diverse attitudes and perspectives from being shared.

Performing This stage is often referred to as the 'working' stage in which the bulk of the 'work' or 'process' take place. The goals and purpose of the group are often referring to the work that takes place during this stage.

Adjourning This stage describes the final stage of group development where the adjourning is the transition between the experiences within the group and the experiences that come after the group ends.

This is when participants feel comfortable with each other and engage in sharing and comparing. This stage is the phase of rich meaning making among participants.

In this final stage, the researcher starts to bring closure to the group interview(s), debriefs the participants, and informs the participants of the next steps in the research study or how to contact the researcher should any questions arise.

Note. The stages and descriptions of group development presented are summarized from the work of Tuckman and Jensen (1977). 
As noted in Table 2, the Performing stage is considered the time that rich meaning making occurs in group interviews. The Performing stage is when the group has reached a level of cohesion and trust that participants voluntarily share perspectives of their experiences, thoughts, and feelings. Rich meaning making happens because this is the phase of group development that in which groups reach a state of cohesiveness (Tuckman \& Jensen, 1977). However, neglecting to recognize the early stages of group development (e.g., Forming, Storming, and Norming) may cause a researcher to prematurely assume a group of adolescent participants is primed for rich meaning making. This can result in reluctant participants and weak data collection.

\section{Suggested Strategies}

Finding ways to guide participants through the Forming, Storming, and Norming stages in addition to being aware of how these stages influence the Performing stage, or rich meaningmaking stage, can help provide a roadmap for researchers as they design research studies and moderate group interviews. Although addressing issues that occur in the beginning stages of group development take time, it may result in an environment in which adolescent participants are more willing or feel safer in offering their perspectives and stories aloud to the group. Some strategies you can implement include: designing introductory activities that welcome the group and provides space for them to get to know you and one another (Forming stage), monitoring discussion and modeling expected behaviors in the group (Storming stage), and working with adolescent participants to create group guidelines (Norming stage). When implemented thoughtfully, each of these suggested strategies can foster group cohesion and are addressed later in this section.

\section{Pay Attention to the Influence of the School Setting}

When conducting educational research with adolescent participants in schools, researchers should be mindful of how the school setting may influence a participant's responses in a group interview. Adolescents are used to sitting amongst a group of peers, listening and responding to an all-knowing authority figure at the front of the room. Although a researcher may try to dislodge themself from playing the role of a teacher, it is still important to realize that adolescents have been conditioned to respond to adults in classrooms in certain ways. Researchers should consider ways of conducting group interviews that avoid mimicking classroom lessons based on "known-answer" questions (Eder \& Fingerson, 2001).

Furthermore, when researching in the school setting, adolescent participants may have more negative associations with some particular classrooms or school spaces than others. For example, hosting group interviews in the front office with adolescents who are part of a study exploring combative behaviors would be a poor choice for the setting of the interviews. Similarly, a particular teacher's classroom may have been the class in which the student made her first failing grade or had been bullied by the boy behind her. Ensuring that the environment is comfortable and safe for participants is, by default, a good practice, and although it is impossible for researchers to know which spaces may trigger participants to feel certain ways, some suggestions can be made to help create a safe space for reflection and sharing with others.

\section{Suggested Strategies}

If interviewing in a classroom, try situating the desks or tables in a new orientation different from which they would expect to be in if attending class in the room. For example, placing the desks or chairs in a circle or moving furniture and sitting on the floor can help send a message to participants that this is not Algebra class. Situating yourself amongst the 
participants is another simple strategy that can help prevent the participants from viewing you as the teacher or an 'outside researcher' who is only interested in collecting and analyzing your data. Ensuring that you and the group of participants can make easy eye contact with each other can enhance the frequency of interaction, friendliness, and cooperation (Johnson \& Johnson, 2013). Lastly, if you are conducting multiple group interviews, try your best to keep the location and setting the same with each interview. This will help your adolescent participants settle into the space more quickly or easily over time.

\section{Define Your Leadership Style}

When conducting qualitative inquiry, adult researchers ultimately want adolescent participants to see them as different from other adults in their lives (e.g., a parent, a teacher, etc.). Yet, since adult researchers are likely much older than adolescent participants, Seidman (2013) cautioned that it takes a special type of sensitivity to be able to connect with young participants without being patronizing. Berg et al. (2013), known for their expertise in the field of counseling and group work, emphasized that the facilitator should consider positioning themselves as different from other adults in the ways in which they treat and interact with the adolescent group members. The authors warned that if you try to be "cool" and act like an adolescent in order to gain their approval, then this may create resistance from adolescents as they can "see right through" your attempt. You are not an adolescent. Acting like one is counterproductive to gaining their trust.

Similarly, your style of moderating the group discussion can also influence how adolescent participants respond to interview questions. In the field of group work, there are three general leadership styles a facilitator can embody. Initially described by Lewin et al. (1939), these styles are autocratic, democratic, and laissez-faire. An autocratic leader dictates the order of the group and determines all group policies and expectations without the involvement of the group members in decision making. A democratic leader sets group policies and expectations through group discussion and decision making and, in general, encourages group cohesiveness. Under this style of leadership, group members are encouraged to interact, cooperate, and be considerate of others. A laissez-faire leader plays a more passive role and does not participate in the group's decision-making processes (Berg et al., 2013; Johnson \& Johnson, 2013). They simply sit back and watch how interaction unfolds. Adolescent participants may respond to each style of leadership differently, which may in turn, influence data collection.

\section{Suggested Strategies}

In order to facilitate a group interview environment that lends itself to eliciting rich responses, and especially if they are inquiring into sensitive topics, facilitators of group interviews should be genuine, caring, and open. When working with adolescents, Dillon (2010) encouraged participants to call her by her first name in order to help diminish her participants as seeing her as a figure of authority, and I, too, have adopted this strategy in my own work. I also pay careful attention to choosing attire that is non-intimidating and not too formal, and I avoid wearing an official name tag other than the school's official visitor pass.

Additionally, a researcher should reflect on the appropriate leadership style for facilitating a group interview with adolescent participants. Researchers should avoid autocratic leadership exclusively. Although the direct leadership of a researcher is necessary in order to execute each phase of research, when communicating with adolescent participants, a more democratic approach may be helpful in establishing group cohesion and trust. With this approach, you can encourage participants to see you as a leader who values their experiences and acknowledges the risk they take in sharing their experiences aloud amongst their peers. 
Some of the additional strategies suggested later in this section, such as encouraging group members to collaborate to determine appropriate group expectations (i.e. group norms), lend themselves to a more democratic style of leading a group of adolescents.

\section{Use Introductory Activities}

In general, incorporating creative introductory actives can help adolescents gain insight into themselves and express their emotions (Veach \& Gladding, 2006), create a safe and consistent environment, and provide opportunities for self-exploration. Facilitated as warm-up exercises, structured activities can promote interaction among members and can help speed up the group's cohesion by bypassing the hesitant, uneasy feelings of introducing oneself to the group (Yalom, 2005). Introductory activities need not be directly related to the research topic of the interview nor does data need to be collected in order for the activity to be meaningful and successful. However, activities that set the tone for the topic of group discussion can help participants ease into the interview. The quicker a group can reach the Performing stage, the stage of cohesion and shared meaning making, the more likely the researcher will be able to collect rich data in a timely manner.

\section{Suggested Strategies}

Some examples of introductory activities include movement exercises, written reflection prompts, and group rituals. Movement exercises can help to "alleviate tension, break down barriers, and energize the group as a whole in an expedient manner" (Veach \& Gladding, 2006, p. 73). In my own experience in working with children and adolescents, I have found younger children to be more open to movement activities. Adolescence is a time of development in which youth are generally more awkward or uncomfortable in their bodies. Their movements are more reserved, risking disproval of their peers. However, when carefully implemented and with appropriate humor, movement activities with adolescents can help create a group experience of purposefully feeling awkward and silly. I also encourage you, the researcher, to participate alongside your participants. This can create a shared, collective feeling of being awkward and silly together. It helps the group acknowledge and release feelings of nervous tension that typically accompany forming a group in which they may be asked to share their personal thoughts, feelings, and experiences with others.

Written reflection prompts can help promote self-reflection among adolescents (Peterson, 2008) and can help group members acknowledge their unique contributions to the group interview. An introductory writing activity can be focused on the topic of the interview in order to transition the participants to the interview experience and stimulate rich discussion (Colluci, 2007). In order to encourage reflection, the prompt should be open ended in nature and brief enough so that the participants do not experience fatigue or get the impression that they are completing an assignment. In order to avoid mimicking the classroom setting, the researcher can encourage participants to respond to a prompt in whatever ways are most comfortable for them (e.g., sentences, fragments, bullet points, poems, letters, drawings, etc.) and should remind participants that their responses will not be graded.

If the inquiry takes place over a series of group interviews, establishing group rituals can also support group cohesion as repetitive activities can promote a sense of unity among adolescents (Malekoff, 2004). They can act as buffers from the 'outside world' they were involved in before arriving to the group interview. In my own research with groups of gifted adolescent girls (Guthrie, 2020), I spent the beginning 2-3 minutes of each session leading the participants through a short centering exercises in which they were invited to close their eyes, take a few deep breaths, and choose a few words to describe how they were feeling in the moment. Participants recorded their responses silently and a few volunteered to share their 
reflections. This ritual helped create a sense of togetherness as they transitioned from their previous activities to our research setting.

Regardless of the type of activity, giving adolescent participants time to adjust to the group interview setting is crucial for promoting an environment in which they feel comfortable sharing responses aloud with the group. Gladding's (2016) The Creative Arts in Counseling (5th edition) offers an array of creative activities that can be adapted for group interviews in order to promote group cohesion, trust, and individual reflection. For example, Gladding (2016) shares how having adolescents make up skits that address topics in humorous ways can help promote a sense of empowerment and empathy among group members. Used as an introductory activity, the researcher can gain insight into adolescent perspectives and at the same time, promote a sense of togetherness and bonding among the group members. Lastly, involving adolescent participants in setting group expectations (see below) could serve as another introductory activity that promotes cohesion and trust among participants.

\section{Encourage Effective Group Norms}

As mentioned earlier, group norms amongst adolescents can be complex. However, regardless of whether or not the group of adolescents have pre-established group norms, encouraging appropriate behaviors and expectations at the beginning and throughout group interviews will support the group in working towards cohesion and trust. One of the most effective ways of implementing group norms is to define the group members' roles and expectations though group discussion (Johnson \& Johnson, 2013). Issues of confidentiality and strategies for sharing and listening are some examples of expectations that can be stated directly and accepted by participants in the early stages of the research.

\section{Suggested Strategies}

In qualitative inquiry, establishing behavioral expectations is often covered in the consent stage of the interview. With groups of adolescent participants, having a group discussion about appropriate behaviors early on in the research is an effective way of encouraging and managing group norms that support rich meaning making. For example, when I have interviewed groups of adolescents, after I have re-introduced the purpose of the interview and confirmed minor assent to participation, we discuss and agree upon a set of group guidelines for participation. Inspired by Delisle and Galbraith (2002), I distribute copies of a list of suggested group guidelines that include statements such as, "Anything that is said in the group, stays in the group. We agree to keep things confidential," "We respect everyone's need to be heard," and "We realize that feelings are not 'bad' or 'good.' They just are. Therefore, we don't say things like, 'You shouldn't feel that way." As a group, we take turns reading these guidelines out loud to each other. Then, we discuss whether or not we would like to re-word, remove, or add any statements. Allowing participants to shape the group's expectations of behavior helps to diminish the power imbalance between myself, the adult researcher, and the adolescent participants. Once we have our final list of group guidelines, I encourage each participant to sign their name in recognition of their intention to uphold the group guidelines as best they can.

Regardless of how many interview sessions are scheduled, reminding participants of the group guidelines (i.e. group norms) before, during, and after each interview session can help participants uphold their commitment and feel safe under your leadership. If the topic of discussion brings up emotions in the participants, it is not uncommon for them to forget some of the guidelines stated days or weeks before. I suggest you keep a copy of the signed group guidelines on hand. If the behaviors of the participants start to shift away from those deemed necessary for cohesion and trust, a simple gesture to the document may be all you need to 
remind participants of appropriate ways to interact within the group setting. And, recall that in schools, adolescents are used to adults setting and enforcing the rules. It is the administrators, teachers, and coaches that ultimately have control. But in qualitative inquiry, we ultimately want the power to be more balanced between interviewer and interviewee. Reminding participants of their co-constructed group guidelines can help prevent you from being seen as an adult who has more power and authority over the group.

\section{Incorporate Humor}

Incorporating humor is another strategy that can be helpful in promoting group communication and cohesiveness (Johnson \& Johnson, 2013) and can be an asset in working with groups of adolescents (Malekoff, 2004). In general, humor has been found to promote group cohesion, provide insight into group dynamics, and reduce group tension (Bloch et al., 1983). It can enhance a sense of intimacy, belonging, warmth, and friendliness (Bloch et al., 1983). With respect to the group facilitator, Smith and Powell (1988) found that when group leaders engaged in self-disparaging humor (i.e. when the group leader was the target of their own humor), there was a decrease in group tension and an increase in participation and willingness for group members to share their opinions with the group. Similarly, Denison and Sutton (1990) claimed that the use of humor is most effective when it is initiated by higherpower members of the group. However, one should be careful to only incorporate humor that is appropriate and directed towards the goal of promoting group cohesion and trust. Humor that resembles teasing or belittling of a group member should be avoided as it may send mixed or harmful messages to the group that impede group's ability to connect or see the group leader as trustworthy (Smith \& Powell, 1988).

\section{Suggested Strategies}

Especially with adolescents, the use of humor in group interviews can be a powerful tool to ease group related tensions and encourage group cohesiveness. Adolescents appreciate humor, and as Malekoff (2004) cautioned, an adult group facilitator should be careful not to try to manipulate adolescents into behaving as "little adults," nor should facilitators "abandon the youthful spirit within themselves" (p. 26). Coming alongside adolescents' natural tendencies towards engaging in humor may help an interviewer facilitate cohesion amongst a group of participants. As the adult with the most power in the group interview setting, consider initiating self-disparaging or group related humor can promote transparency by helping adolescent participants see your "human-ness" (Bloch et al., 1983). Poking fun at yourself in front of the group may help the participants see you as an adult that is open and accepting towards imperfections. Depending on the topic of conversation, this may be particularly helpful.

\section{Encourage Written Reflections in Data Collection}

One method of increasing rigor in qualitative inquiry involves collecting data through a variety of methods (e.g., participant observation, interviews, surveys, etc.; Tracy, 2010). In conjunction with group interviews with adolescents-especially because their experiences are often socially rooted in their peers' experiences-using additional methods of data collection such as field observations or single interviews can help validate participants' responses and strengthen analysis procedures (Eder \& Fingerson, 2001). Written reflections are another method that can bolster data collection. Written reflections can serve as prompts for group discussion and help adolescents ease into sharing their thoughts, feelings, and experiences with the group. Additionally, it is likely that there will be times in which some participants are 
hesitant to share their thoughts, feelings, or experiences aloud with the group. They may feel more comfortable writing them down on paper.

\section{Suggested Strategies}

Written reflections can be encouraged and collected at the beginning, during, or at the conclusion of a group interview. If encouraged prior to the group discussion, a researcher can capture individual responses that have not yet been influenced by the group discussion. However, written reflections that are collected later, either during or after a group discussion, can also provide rich insight. Recall that social interaction in the group environment has the potential to create "high quality, interactive data" (Wilkinson, 1998) because participants often naturally build off each other's conversation through agreement, disagreement, or adding elaborated details to each other's comments. In practice, I have listened as participants commented, "I didn't write this down, but so-and-so's comment reminded me of a time when...." I have also watched participants write down additional thoughts as they listened to their peers share aloud with the group. Capturing adolescents' reflections prior to, during, and/or after interactions with others can help support robust data collection. In my experience, if the group displayed evidence of cohesion and trust, reflections that are written down during or after the group discussion are more elaborate and self-disclosing.

Before proceeding, I would also like to reiterate that when interviewing in the context of schools, it is important for the interviewer to remind participants that their written responses will not be judged for proper grammar. As stated earlier, I encourage adolescents to respond in any way they would like (e.g., sentences, fragments, bullet points, poems, letters, drawings, etc.). This helps to alleviate their conditioned response to assuming that $I$, the adult, will be grading what they submit to me.

\section{Design Your Study to Benefit Participants}

Another way to respond to the power dynamics between researcher and adolescent participants is to emphasize reciprocity, or in other words, a giving back to the participants in return for data collected. Eder and Fingerson (2001) claimed that a researcher's desire to collect participants' information without giving anything in return is a reflection of the researcher's privilege and power. When working with adolescents in schools, I encourage educational researchers to avoid giving incentives or rewards for participation, unless the purpose of offering an incentive or reward is to support group cohesion ${ }^{3}$. The following suggestions, although simple in nature, can be enough to help increase reciprocity and decrease the researcher's privilege and power and increase group cohesion and trust.

\section{Suggested Strategies}

Reciprocity can take on many forms. For example, interviewers can begin to offer reciprocity with interviewees by being the kind of listener that takes participants seriously and values what they say (Seidman, 2013). Participants benefit from researchers that honor the details of their lives and experiences not only in the midst of the interview, but also in the writing up and dissemination of findings (Seidman, 2013). Group interviews and shared

\footnotetext{
${ }^{3}$ For example, I once gave t-shirts to participants of one of my studies (Guthrie, 2020). The study was imbedded in a five-session evening activity of an academic residential summer program and involved teen-friendly yoga, relaxation, journaling, and group discussions. The t-shirts displayed the activity's logo and were intended to (1) give the participants something comfortable to wear during our five-sessions and (2) create a tangible sense of connection and belonging among the participants.
} 
meaning making can also create experiences that benefit participants. Participants may leave with a greater sense of altruism or universality (Yalom, 2005).

For example, in Guthrie (2020), at the conclusion of our five group interview sessions, I reserved time for participants to reflect and record what participating in the group interviews was like for them. I simply provided the prompt "What I Know Now" to as a way of encouraging them to reflect and integrate the content that was shared in the group discussions. In sharing their responses with the group, participants thanked me for the opportunity to reflect on and share their experiences with others. In hearing their peers share aloud with the group, they reported feeling less alone in their experiences.

Consider how the overall design of your group interview study, your role and facilitation style, and the activities you incorporate into the group interviews may benefit adolescent participants. Being an adult who listens and shows deep interest in their thoughts, feelings, and experiences can create a sense of validation and worth that they may not experience in interactions with adults in academic settings. Depending on the topic, making connections among participants by linking their experiences to one another has the potential to create a sense of belonging amongst adolescents.

\section{Implications for Researchers and Instructors of Qualitative Research Methods}

For researchers and instructors of qualitative research, the strategies mentioned in this article serve as suggestions for designing qualitative inquiry with adolescents that go beyond introductory approaches often included in introductory qualitative research texts. Some of the suggestions would undoubtedly be included in a research proposal (e.g., using introductory activities), but others may go overlooked in the design process (e.g., leadership style and incorporating humor). In my work with adolescents, I have found it is both the formal, research designed activities and the small, more nuanced gestures that create space for rich meaning making.

Instructors of qualitative research methods in education can use information presented in this article to inform their qualitative pedagogy. According to Preissle and deMarrais (2011), qualitative pedagogy should incorporate "learning-by-doing" experiences that mirror the ways qualitative research is practiced. Class activities such as personal reflection activities and engaging in ethnographic exercises can encourage graduate students to consider their roles as qualitative researchers inquiring into the lives of adolescents in schools.

Personal reflection activities can challenge an adult researcher to reflect back on their own adolescent experiences in school contexts. These reflections can then inform one's subjectivity statements. A researcher's subjectivities, according to Preissle (2008), "may bias, unbalance, and limit endeavors, but they may also motivate and illuminate inquiry" (p. 846). The following questions may be helpful in guiding graduate students preparing to conduct qualitative inquiry with adolescents: What did the notion of school and learning have for them when they were adolescents in school? What were their relationships like with teachers? How comfortable did they feel sharing their thoughts, feelings, and experiences with their peers? With adults? What type of power did they experience in schools? Reflection activities that help adult researchers put themselves in the mindset of what it was like to be an adolescent may help them empathize with their participants. The more a researcher can empathize with participants, while at the same time remaining open and non-judgmental, the greater the potential the participants will trust the researcher and self-disclose amongst the group.

Ethnographic activities can take on many forms. Researchers who do not spend a lot of time with adolescents may be far removed from adolescent culture. Finding time to volunteer at schools and observe students in the hallways, in classrooms, or in school parking lots can help researchers become more familiar with current adolescent behaviors, mannerisms, and interests. Even observing adolescents off school grounds can provide insight into how they may 
respond to peers and adults differently (e.g., coffee shops, sports events, community groups). Or, after gaining permission from school personnel, graduate students can be assigned to observe adolescent students with their peers and adults in the classroom, in the hallway, or in the lunchroom. These activities can be embedded throughout the course as a way of teaching qualitative research methods through immersive experiences that have them acting as qualitative researchers (see Fontes \& Piercy, 2000). Instructors can increase the rigor of these activities by requiring graduate students to record observational field notes (see Merriam \& Tisdell, 2016) and write reflexive memos (see Annink, 2017). Then, graduate students can begin to make inferences by analyzing their observations. Guiding questions can include: How do adolescents respond differently to different adults? Where do you see power imbalances in their interactions with administrators, teachers, or peers? How do adolescents behave in different settings? How might the makeup of the participants in the group influence participation, cohesiveness, and trust? These observations and inferences can help a researcher attend to how participants may interact and behave in a group interview.

\section{Conclusion}

Keefe and Andrews (2015) proposed that when working with adolescents, a "greater depth of understanding is required for the researcher to listen carefully to the spoken and the unspoken, to identify and balance power relations, to collaborate with students as partners in research" (p. 357). Group cohesion and trust are essential to rich meaning making among group interviews with adolescents. Threats to cohesion and trust include unbalanced power in the relationships (either between researcher-participant or amongst the participants themselves), the presence of peer influence, and the risk of breaking confidentiality. However, the strategies mentioned in this article, when implemented carefully, can guard against these threats and ultimately create a group environment that supports social interaction and shared meaning making.

The suggestions from my own personal experience should be taken as just that-my own experience. My comfort level in working with adolescents has been influenced by my own experiences of working with students in the middle and high school classrooms, lunchrooms, and hallways, in addition to my responsibilities as an extra-curricular club leader and coach as well as from my research with groups of adolescents. Every group of adolescents is different, and you, the reader, have your own experiences from which to draw. Strategies suggested in this article should be considered as starting points for designing effective group interviews with adolescents and should be adapted and modified appropriately for the purpose of the research and topic of discussion.

\section{Disclosure Statement}

I have no conflict of interest or benefit to disclose.

\section{References}

Annink, A. (2017). Using the research journal during qualitative data collection in a crosscultural context. Entrepreneurship Research Journal, 7(1), 1-17. https://doi.org/ 10.1515/erj-2015-0063

Barbour, R. S. (2007). Doing focus groups. SAGE Publications.

Berg, R. C., Landreth, G. L., \& Fall, K. A. (2013). Group counseling: Concepts and procedures (5th ed.). Routledge. 
Bloch, S., Browning, S., \& McGrath, G. (1983). Humour in group psychotherapy. British Journal of Medical Psychology, 56(1), 89-97. https://doi.org/10.1111/j.20448341.1983.tb01535.x

Blumer, H. (1969). Symbolic interactionism: Perspective and method. Prentice Hall.

Colucci, E. (2007). "Focus groups can be fun": The use of activity-oriented questions in focus group discussions. Qualitative Health Research, 17(10), 1422-1433.

Delisle, J., \& Galbraith, J. (2002). When gifted kids don't have all the answers: How to meet their social and emotional needs (2nd ed.). Free Spirit Publishing.

deMarrais, K. (2004). Qualitative interview studies: Learning through experience. In K. deMarrais \& S. Lapan (Eds.), Foundations for research: Methods of inquiry in education and the social sciences (pp. 51-68). Lawrence Erlbaum Associates.

Denison, D., \& Sutton, R. (1990). Operating room nurses. In J. Hackman (Ed.), Groups that work (and those that don 't): Creating conditions for effective teamwork (pp. 293-308). Jossey-Bass.

Dillon, L. (2010). Writing the self: The emergence of a dialogic space. Narrative Inquiry, 21(1), 213-237. https://doi.org/ 10.1075/ni.21.2.03dil

Dixon, C. S. (2015). Interviewing adolescent females in qualitative research. The Qualitative Report, 20, 2067-2077.

Eder, D., \& Fingerson, L. (2001). Interviewing children and adolescents. In J. F. Gubrium \& J. A. Holstein (Eds.), Handbook of interview research: Context and method (pp. 181201). SAGE Publications.

Erickson, E. H. (1980). Identify and the life cycle. W. W. Norton \& Company.

Finch, H., Lewis, J., \& Turley, C. (2014). Focus groups. In J. Ritchie, J. Lewis, C. M. Nicholls, \& R. Ormston (Eds.), Qualitative research practice: A guide for social science students and researchers (2nd ed., pp. 211-242). SAGE Publications.

Fontes, L. A., \& Piercy, F. P. (2000). Engaging students in qualitative research through experiential class activities. Teaching of Psychology, 27(3), 174-179. https://doi.org/10.1207/S15328023TOP2703_03

Forsyth, D. R. (2006). Group dynamics (4th ed.). Thomson/Wadsworth.

Freeman, M., deMarrais, K., Preissle, J., Roulston, K., \& St. Pierre, E. A. (2007). Standards of evidence in qualitative research: An incitement to discourse. Educational Researcher, 36(1), 25-32. https://doi.org/ 10.3102/0013189X06298009

Gladding, S. T. (2016). The creative arts in counseling (5th ed.). American Counseling Association.

Guthrie, K. H. (2020). The weight of expectations: A thematic narrative of gifted adolescent girls' reflections of being gifted. Roeper Review, 42(1), 25-37. https://doi/org/10.1080/02783193.2019.1690080

Johnson, D. W., \& Johnson, F. P. (2013). Joining together: Group theory and group skills (11th ed.). Pearson Education.

Keefe, M., \& Andrews, D. (2015). Towards an adolescent friendly methodology: Accessing the authentic through collective reflection. International Journal of Research \& Method in Education, 38, 357-370. https://doi.org/10.1080/1743727X.2014.931367

Lewin, K., Lippitt, R., \& White, R. K. (1939). Patterns of aggressive behavior in experimentally created "social climates." The Journal of Social Psychology, 10, 271-299.

Lincoln, Y., \& Guba, E. G. (1985). Naturalistic inquiry. Sage.

MacKenzie, K. R., Dies, R. R., Coché, E., Rutan, J. S., \& Stone, W. S. (1987). An analysis of AGPA Institute groups. International Journal of Group Psychotherapy, 37(1), 55-74. https://doi.org/ 10.1080/00207284.1987.11491041

Malekoff, A. (2004). Group work with adolescents: Principles and practice (2nd ed.). The Guilford Press. 
Mayall, B. (1999). Children and childhood. In S. Hood, B. Mayall, \& S. Oliver (Eds.), Critical issues in social research: Power and prejudice (pp. 10-24). Open University Press.

Mead, G. H. (1934). Mind, self \& society. The University of Chicago Press.

Merriam, S. B., \& Tisdell, E. J. (2016). Qualitative research: A guide to design and implementation (4th ed.). John Wiley \& Sons.

Mishler, E. G. (1986). Research interviewing: Context and narrative. Harvard University Press.

Morgan, D. L. (2012). Focus groups and social interaction. In J. Gubrium, J. Holstein, A. Marvasti, \& K. McKinney (Eds.), The SAGE handbook of interview research: The complexity of the craft (2nd ed., pp. 161-176). SAGE Publications.

Norris, A. E., Aroian, K. J., \& Warren, S. (2013). Interactive performance and focus groups with adolescents: The power of play. Research in Nursing and Health, 35(6), 671-679. https://doi.org/10.1002/nur.21509.

Ozfidan, B., \& Burlbaw, L. M. (2016). Perceptions of bilingual education model in Spain: How to implement a bilingual education model in Turkey. Journal of Ethnic and Cultural Studies, 3(1), 49-58. http://dx.doi.org/10.29333/ejecs/49

Peterson, J. S. (2008). The essential guide to talking with gifted teens: Ready-to-use discussions about identity, stress, relationships, and more. Free Spirit Publishing.

Prasad, P. (2005). Crafting qualitative research. M. E. Sharpe.

Preissle, J. (2008). Subjectivity statement. In L. Given (Ed.), The SAGE encyclopedia of qualitative research methods (p. 846). SAGE Publications.

Preissle, J., \& deMarrais, K. (2011). Teaching qualitative research responsively. In N. K. Denzin \& M. D. Giardina (Eds.), Qualitative inquiry and global crises (pp. 31-39). Left Coast Press.

Roulston, K. J. (2010). Reflective interviewing. SAGE Publications.

Roulston, K., \& Liljestrom, A. (2010). Interviews with groups. In K. Roulston, Reflective interviewing (pp. 33-50). SAGE Publications.

Schutz, A. (1967). The phenomenology of the social world. Northwestern University Press.

Seidman, I. (2013). Interviewing as qualitative research: A guide for researchers in education and the social sciences (4th ed.). Teachers College Press.

Smith, C. M., \& Powell, L. (1988). The use of disparaging humor by group leaders. Southern Speech Communication Journal, 53, 279-292. https://doi.org/10.1080/10417948809372729

The National Commission for the Protection of Human Subjects of Biomedical and Behavioral Research (1979). The Belmont report: Ethical principles and guidelines for the protection of human subjects of research. The Commission.

Tracy, S. J. (2010). Qualitative quality: Eight "big-tent" criteria for excellent qualitative research. Qualitative Inquiry, 16, 837-851. https://doi.org/10.1177/1077800410383121

Tuckman, B. W., \& Jensen, M. C. (1977). Stages of small-group development revisited. Group and Organization Management, 2, 419-427. https://doi.org/10.1177/105960117700200404

Veach, L. J., \& Gladding, S. T. (2006). Using creative group techniques in high schools. The Journal for Specialists in Group Work, 32(1), 71-81. https://doi.org/10.1080/01933920600978570

Wilkinson, S. (1998). Focus groups in feminist research: Power, interaction, and the coconstruction of meaning. Women's Studies International Forum, 21(1), 111-125.

Wilkinson, S. (2008). Focus groups. In J. A. Smith (Ed.), Qualitative psychology: A practical guide to research methods (pp. 196-206). SAGE Publications.

Yalom, I. (2005). Theory and practice of group psychotherapy (5th ed.). Basic Books. 


\section{Notes on Contributors}

Kate H. Guthrie received her Ph.D. in Educational Psychology with a certificate in Interdisciplinary Qualitative Research Studies from the University of Georgia. Her research focuses on qualitative inquiry and the lived experiences of gifted adolescent females, of which her dissertation earned her the Owen Scott Emerging Scholar Award. She currently serves as an Assistant Professor and Qualitative Research Methodologist at Piedmont College. She is an experienced high school math teacher and has worked with diverse populations of adolescents in an array of environments.

Manuscript received September 17, 2020

Final revision received October 09, 2020

Accepted October 10, 2020 